Pegem Journal of Education \& Instruction, 4(1), 2014, 59-74

Pegem Eğitim ve Öğretim Dergisi, 4(1), 2014, 59-74

www.pegegog.net

\title{
Teachers' and Students' Views on Using Augmented Reality Environments in Physics Education: 11th Grade Magnetism Topic Example*
}

\section{Mustafa Serkan ABDÜSSELAM ${ }^{\text {ta }}$}

\author{
${ }^{a}$ Karadeniz Technical University, Beşikdüzü Vocational Sch., Trabzon/Turkey
}

\section{Article Info}

DOI: $10.14527 /$ pegegog.2014.004

Article history:

Received 11 April 2013

Revised 14 October 2013

Accepted 19 January 2014

\section{Keywords:}

Augmented reality environment

Class environment,

Laboratory environment,

Physics education,

The magnetism.

\begin{abstract}
The aim of this study was to evaluate the opinions of students in learning physics and physics teachers in teaching physics during using augmented reality environments. In this study, focus group interview technique was used as a qualitative research technique. Semi-structured interview technique was used as a method of data collection. This study was executed with three physic teachers and 8 students of a secondary school at Trabzon in 2010-2011 school years. As a result, using augmented reality in teaching magnetism has benefits on behalf of the magnetic field by providing the visualization. In learning side, it helps the student for better understanding the events of the environment and make able to have more better realistic application. Through the obtained results, it is suggested that augmented reality should be used in other subjects of science which are difficult to comprehend.
\end{abstract}

\section{Introduction}

Physics is one of the academic disciplines that involves the analysis of nature and understand it over years until now. Physics also has played an important role in the development of the new technology (Serway \& Beichner, 2002). In other side, the continuity of learning is changing according the theoretical aspects (Dagher, 1995; Duphin \& Johsua, 1989; Greca \& Moreira, 2000; Lawson \& Lawson , 1993). This state support the new technological developments and making them used in learning activity (Uşun, 2003). One of these technologies is the computer technology which can be used to visualize the concepts via simulations or animation. In addition to this, the using of new technology and converted it to instructional materials will help student to better understand real-world situations. One of the roles of computers technology in the teaching of physics is to support the building of knowledge and retention practice (Grabinger, 1999; Jonassen, Pech \& Wilson, 1999).

As a result of inefficient usage of computer technology that has a great role in development, an imaginary environment has been developing rapidly in recent centuries. One of these new born technologies is "Augmented Reality". It is considered that augmented reality will contribute in getting both knowledge and talent. Especially for the subjects that are understood more difficultly like physics, it will be very useful as it has visual and three dimensional effects (Winkler, Herczeg \& Kritzenberger, 2002; Winn, Windschitl, Fruland \& Lee, 2002). Augmented reality is used in education with two different sides in basic. The first one is used in an imaginary visual environment and the second is used more

\footnotetext{
*This article has been presented at the "X. National Science and Mathematics Education Congress", Niğde/Turkey, 27-30"th/06/2012.

$\dagger$ Corresponding author: msa@ktu.edu.tr
} 
intense, including imaginary items. But the important point here is that the real objects and the imaginary objects are related with each other (Liu, Cheok, Ling, \& Theng, 2007). The more related are they, the more successful it works (Zagoranski \& Divijak, 2003). In this way, it will be easier for students to build their knowledge (Alouf \& Bentley, 2003). Thus, learning environments will be funnier, interactively, effectively and also powerful (Kirkley, Kirkley, Myers, Borland, Swan, Sherwood \& Singer, 2005) unlike traditional classroom environments (McDermott, 1993). As a result, it is believed that augmented reality will contribute to physics programs especially for difficult subjects for students.

\section{Method}

The aim of this study was to evaluate the opinions of students in learning physics and physics teachers in teaching physics during using augmented reality environments. In this study, focus group interview technique was used as a qualitative research technique (Çepni, 2001). At this context to gain the aim for this research, the answers for the following questions are tried to find:

1. Is the technology in physics classes sufficient for the teachers?

2. What are the problems in lessons and what are the solutions?

3. What are the contributions of augmented reality in magnetism subject?

4. What is the students' point of view in classes or in labs while using augmented reality?

5. How does augmented reality show differences in terms of students' motivation when it is used in classes or labs?

6. How does augmented reality show differences when it is used in classes or labs in terms of students' knowledge?

\section{Research Design}

This research was done in a high school with three volunteer physics teachers and with eleventh grade students in the 2010-2011 second term academic year. Before starting the project, three classes were selected at random and the subject of magnetism was studied in each classes for three weeks, but in 11-D the subject was studied with the researcher using augmented reality environment, in 11-A in the classroom environment and in 11-B in a lab environment. Among these students two of them are educated in the classroom environment, three of them are in lab, and three of them are in augmented reality environment. The high school teachers participated in this project had been given a seminar about augmented reality for a day and then they began to use the augmented reality environment by the help of the researchers. At the end of this study, participants were considered to have enough knowledge about the three different environments.

\section{Participants}

For this research to answer the question a group work was made with three physics teachers and eight students. The researchers gave the teachers and students two different forms about using augmented reality environment in their classes to gain their point of view. While preparing these forms the ideas of a physics expert and a computer expert were taken which formed the questionnaire.

\section{Instrument}

The results were registered and evaluated by the researcher. For three weeks, the research was carried out in augmented reality by the participant teachers and the students. In the time of these applied progresses the observations were evaluated and a semi-structured form was prepared by taking the expert's views. 


\section{Data Analysis}

The researcher took the participants' ideas on how the environments affect in understanding the magnetism. At this point it was aimed to have their own ideas. In this environment they all learn their own ideas as well. As for the evaluation the grading levels were; "yes, partly, no" from top to bottom in degree. The answers were evaluated by the researcher and for the objectivity, it was controlled and analysed by the experts.

\section{Results}

According to research results, physics teachers answered positively to the questions which are based on using augmented reality in teaching physic. Whereas they have some difficult in using technology in classes and labs. Additionally, they prefer three dimensional visual materials in physics lessons especially in subject of magnetism. Students also answered positively to the questions which are based on using augmented reality at learning process.

\section{Discussion, Conclusion \& Implementation}

As a result, physics teachers thought that, in their lessons labs are used but the technology is partly sufficient for them. In this research it was understood that physics teachers get benefit from physics labs by using standard expert materials like Nova5000. They take care of using simple, cheap easy in use materials and they give importance to rich visual materials, three dimension materials that enable the subjects to become more concrete as well as they are very beneficial for the students. In literature there are many studies that support this point of view (Chabay \& Sherwood, 2006; Demirci \& Çirkinoğlu, 2004; Kocakülah, 1999).

Teachers express that, they insist on using visual materials, three dimension objects, experiments, animations that form concrete meaning in physics lessons especially in subject of magnetism. Chaboy and Sherwood (2006) said that students have difficulty in understanding magnetism rather than the other subjects. For its reason the researchers implied that this subject includes abstract concept. It requires three dimensional thinking that creates difficulty for them in understanding. Similar results can be found in the studies of Bagno and Eylon as well (1997). At the result of this work the numbers of teachers were increased and it was said that, to understand physics especially the subject of magnetism, visual learning and concrete learning methods, using three dimension objects enable students to understand it much better. Also the studies of Buesing and Cook (2013), Macedo, Fernandes, Lima and Biazus (2012) support the idea that augmented reality helps students to understand the subject of magnetism better.

Students in the classroom environment stated that the books in this Area, the opportunity to make registers are great advantages for them. Also the chance making experiments in labs that can be related with real world has a great advantage in understanding physics for them too. As for augmented reality environment, as it enables concrete understanding and visual materials it is adventurous as well. In literature the importance of students learning by doing themselves is stressed. Also, as in augmented reality environment a person can do experiments by themselves, they can increase their experiences (Matsutomo, Miyauchi, Noguchi \& Yamashita, 2012). The physics students explained that if the learning environment is not sufficient, they may even hate the lesson or in that insufficient environments students are not willing to participate the lessons actively. Labs are more attractive for them as they can make experiments which make them love the subject more. In augmented reality as the new technology is used which forms a visual atmosphere, the students think that they defeat their affairs about physics. This result has a parallelism with the studies of Finkelstein, Perkins, Adams, Kohl and Podolefsky (2005). So with this new study motivate the students and it makes the environment attractive. 
Students in classroom environment stated that this environment is insufficient to understand the subjects especially magnetism. The students in labs said that labs are more beneficial for making experiments. The students in class said that this environment supported the labs and as it requires visual understanding, it is more productive. Ayas, Akdeniz and Çepni (1994), Akdeniz, Çepni and Azar (1998), Böyük and Erol (2008), Chiappetta and Koballa (2002), Hofstein, Navon, Kipnis and Mamlok (2005) stressed the positive effects of labs in the physics lessons as well.

Students in classroom environment think that in understanding magnetism, this environment is not sufficient. Students in labs said that experiments take their attention, and these experiments make the subject more interesting and attractive as well. Students in augmented reality stated that even the new technology alone can take their attention. Students stressed that augmented reality environment enable them to comprehend the subjects better while following the science and the technology as it has great advantages. In analyzing how technology affects the society and the environment Finkelstein et al. (2005), Müller and Ferreira (2003), Winkler et al. (2002) stated that augmented reality environment helps the students to learn and comprehend better. These results show a parallelism with literature. Also Böyük, Demir and Erol (2010) stressed that labs have great positive affect in learning as they increase their interests for the lessons. While investigating these problems the following results are gained.

1. Physics teachers say that they use labs for their lessons but the technology they use is not sufficient enough.

2. Physics teachers have difficulty in lecturing magnetism when they try to concrete the magnetic field, expressing three dimensions and explaining right-hand rule.

3. Physics teachers think that augmented reality make it much easier to teach magnetism.

4. Students think that augmented reality environment has much more advantages than the classes and the labs.

5. Students say that the environment they learn affects their emotions and their thoughts.

6. Students say augmented reality environment affects their academic success in a positive way.

By looking these results, we may suggest that:

1. In the physics lessons should be organized by the advantage and benefit of augmented reality for the subjects that are understood hardly.

2. Ministry of National Education should use augmented reality in "Fatih Project" in different fields which will be very useful. Also this material should be used as a teaching method as it is congenial with informatics technology.

3. For secondary education augmented reality can be organized for different lessons at schools too. So, difficult subjects like magnetism can be understood more easily and efficiently by the students.

4. As it is a new technology the teachers should be educated about augmented reality with seminars organized by the Ministry of National Education to use it in their lessons efficiently.

5. As physics is one of the lessons for which the students generally have affairs and have difficulty in understanding, first of all students should be motivated about this lesson positively. Besides this, their emotions and thoughts should be developed in a good way as much as possible.

6. It is understood that augmented reality environment affect their emotion and thoughts positively and this should method should be participated in education process. 
Pegem Journal of Education \& Instruction, 4(1), 2014, 59-74

Pegem Eğitim ve Öğretim Dergisi, 4(1), 2014, 59-74

www.pegegog.net

Fizik Öğretiminde Artırımış Gerçeklik Ortamlarının Kullanımlarına iliş̧kin Öğretmen ve Öğrenci Görüşleri: 11. Sınıf Manyetizma Konusu Örneği ${ }^{*}$

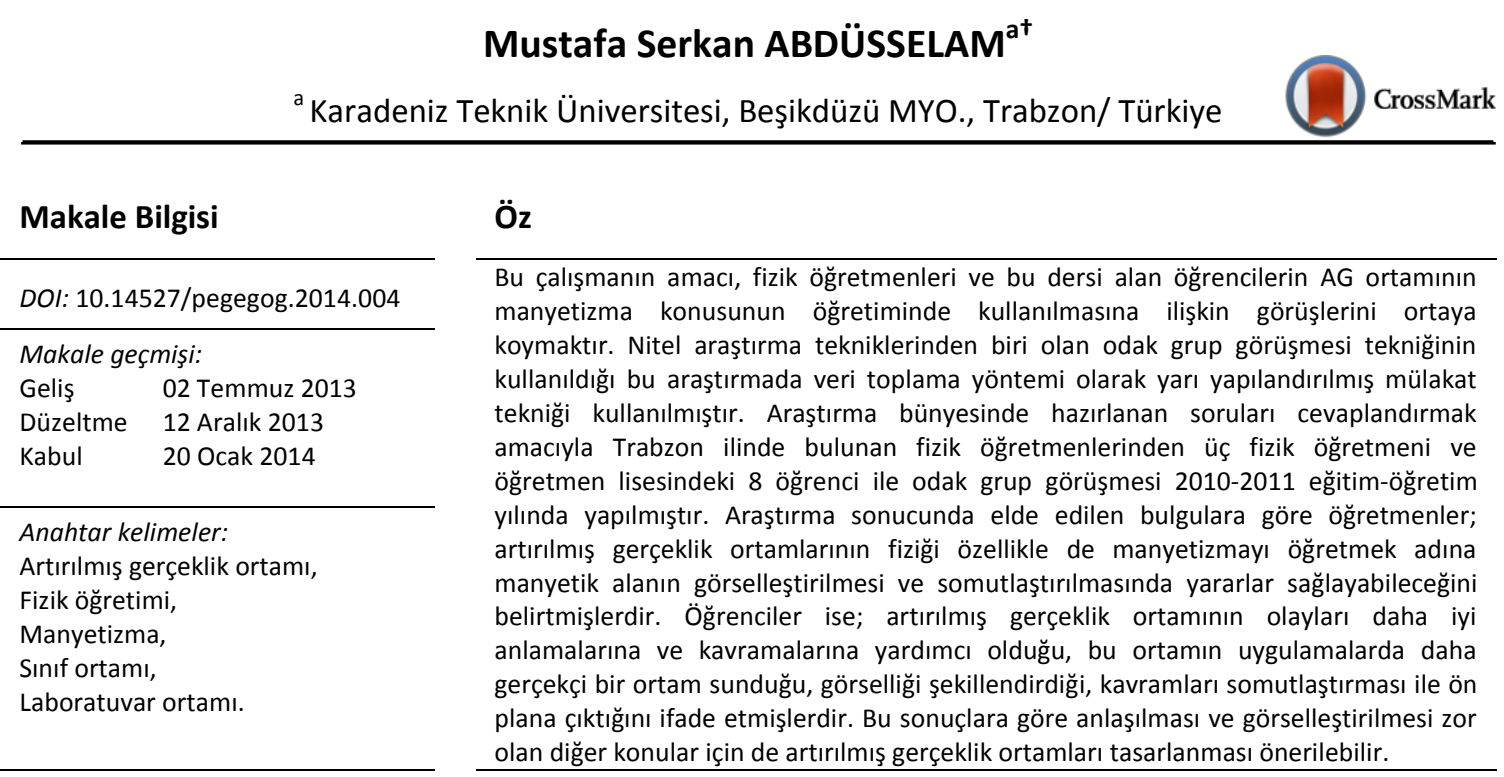

Giriş

Bilim dallarından biri olan fizik insanoğlunun doğayı anlama ve açıklama çabası sonucunda güncelliğini hiç yitirmemiştir. Dünya çapında fizik alanında yapılan ve hala çalışmaların devam ettiği konulardan birisi de fiziğin nasıl öğretileceğidir. Özellikle bu alanda yapılan bilimsel çalışmalar, teknolojinin gelişmesinde önemli bir rol oynamıştır (Serway ve Beichner, 2002). Öğrenmenin süreklilik göstermesi ise bu çalışmaların neden tamamlanamadığının sebebidir (Dagher, 1995; Duphin ve Johsua, 1989; Greca ve Moreira, 2000; Lawson ve Lawson, 1993). Bu durum toplumların yeni teknolojik gelişmeleri izlemelerini ve kendilerine uyarlamalarını zorunlu hale getirerek eğitim sürecinin ve niteliğinin gelişmesinde önemli rol oynayan yeni teknolojilerin eğitim kurumlarına girmesini de beraberinde getirmiştir (Uşun, 2003).

Bu teknolojilerden biri de bilgisayar teknolojisidir. Bilgisayar teknolojileri eğitim hayatımızda olay ve durumların simülasyonlarla ya da animasyonlarla oluşturulması, sergilenmesi ve görselleştirilmesinde kullanılmaktadır. Bunun yanı sıra teknolojik araçlarla desteklenmiş masaüstü bilgisayarlarda oluşturulan senaryoların görselleştirilerek öğrenmede kullanılması, öğrencilerin gerçek dünya durumları ve problemlerini anlamasına yardımcı olmaktadır. Fiziğin öğretilmesindeki amaçlardan birisi öğrencileri bilgiye nasıl ulaşacaklarından haberdar ederek onların öğrenmelerini kolaylaştıracak ve kalıcı öğrenmeler için uygun eğitim-öğretim materyallerini kullanarak, simülasyon animasyon gibi tekniklerle öğrencilerin gerçek hayat deneyimleri kazanmalarını sağlamak, soyut olay ya da olguları somut hale dönüştürmek

\footnotetext{
*Bu Makale, 27-30, 6/2012 tarihlerinde Niğde Üniversitesi tarafindan düzenlenen X.Ulusal Fen Bilimleri ve Matematik Eğitimi Kongresinde sözlü bildiri olarak sunulmuştur.

†'Yazar: msa@ktu.edu.tr
} 
olduğundan bilgisayar teknolojisinin fizik alanında kullanılması fiziğin amaçlarına ulaşılmada katkı sağlayabilir (Grabinger, 1999; Jonassen, Pech ve Wilson, 1999).

Ancak bilgisayar teknolojisinde kullanılan görselleştirmeler üç boyutlu oluşturuldukları halde, öğrenciler tarafından anlaşımaları bazen güç bir hal alabilmektedir. Bu soruna çözüm olarak öğrencilerin öğretilen konuyla ilgili becerilerinin farkına varmaları ve bu becerilerini daha üst seviyeye taşımaları için de teknolojinin sunmuş olduğu yeni gelişmelerden yararlanılabilir. Son yüzyıldaki gelişmelerle önemli bir yol alan ve yaygın olarak kullanılan bilgisayarlarda üretilen verilerin gerçek ortamlarda etkin ve istendik şekilde kullanılamamaları sonucunda, artırılmış ve sanal ortamlar gibi ortamlar hızla gelişmektedir. Bu teknolojiler ışığında gelişen yeni teknolojilerden birisi ise Artırılmış Gerçeklik (AG) ortamlarıdır. AG ortamlarının hem bilgi hem de beceri kazanma evresinde katkı sağlayacağı düşünülmektedir. Özellikle fizik dersi gibi anlaşılması zor olan içerikler AG ortamlarında görselleştirilerek anlaşılır bir hal alacaktır. Bu işlevlerin sınıf ortamında gerçekleştirilemeyeceği ise açıkça görülmektedir (McDermott, 1993). Ayrıca fizik eğitiminde amaçlanan kazanımların oluşması için öğrencilerin yaparak, yaşayarak öğrenmeleri, öğrenme sürecine aktif olarak katılmaları ve bilim insanı gibi davranarak fiziği sorgulamaları gerekmektedir (Alouf ve Bentley, 2003). Bu gelişim teknolojinin bu alanını günümüz öğrenenlerinin kullanmalarına bunun sonucu olarak deneyim sahibi olmalarına yardımcı olabilecektir. Bu imkânlarla öğrenme ortamları; keşfeden, öğrenirken eğlenebilen, etkileşimli, etkili ve güçlü bir hal alabilecektir (Kirkley, Kirkley, Myers, Borland, Swan, Sherwood ve Singer, 2005). AG ortamları öğrencilerin konuya ilgilerini arttırdığından normal bir masaüstü öğrenme etkinliğine göre daha başarılı olmakta, aynı zamanda görselleştirilen nesnelerin de üç boyutlu olması öğrencilerin dikkatlerini arttırmaktadır (Winn, Windschitl, Fruland ve Lee, 2002).

Yeni teknolojilerden biri sayılan AG ortamlarının sağladığı avantaj gerçekçi bir simülasyon ve deney ortamı sunmasıdır. Etkinliklerde öğrencilerin katıımlarını artırması ve deneyleri kolaylaştırması bu ortamların öğretim alanındaki kullanımını etkili hale getirmektedir. AG ortam uygulamaları doğru bilgi ve çıkarımların elde edilebilmesi için öğrenme çevresine yenilikleri getirerek bu bilgilerin ve çıkarımların daha iyi anlaşılmasını, irdelenmesini ve farkına varılmasını sağlar. Ayrıca AG ortamlarının birer oyun olduğu ve eğitim öğretimin dışında kaldığı iddia edilse bile sınıf ortamlarında öğrenciler kısa sürede odaklanma kabiliyetlerini kaybederken, AG ortamlarında bu odaklanma süresi uzayabilmektedir. Eğitimde öğrencinin öğretilecek konuya odaklanma süresinin arttırılması başarının da beraberinde gelmesine yardımcı olacaktır (Winkler, Herczeg ve Kritzenberger, 2002). AG ortamları temelde iki farklı yönüyle öğretim alanında kullanılmaktadır. Bunlardan ilki; gerçek ortamı sadece bir hareket alanı şeklinde kullanarak sanal nesnelerin bu ortamda görselleştirilmesidir. İkincisi ise; gerçek ortamı daha çok işin içine katarak görselleştirilen sanal nesneleri bu ortamda oluşturmaktır. Ancak buradaki önemli durum sanal nesnelerin gerçek ortam nesneleriyle ilişkili olmasıdır (Liu, Cheok, Ling ve Theng, 2007). Öğrenciyi çevreleyen ortam ile sanal olarak oluşturulan ortam ne kadar iyi bir şekilde kombine edilir ve sanal ifadeler ne kadar anlamlaşırsa bu iki ortam o denli bir bütün haline getirilebilir. İşte bu noktada bu iki ortam bir bütün haline getirilirse öğrencilere sunulan kombine edilmiş ortamdan yararlanılması da bilginin yapılandırılmasını daha da kolaylaştıracaktır (Zagoranski ve Divijak, 2003). Bunun sonucu olarak AG ortamlarının fiziğin manyetizma gibi anlaşılması zor olan bir konuya uygulanmasıyla fizik eğitiminde amaçlanan fizik dersi öğretim programları beceri kazanımlarının öğrencilere kazandırılmasında önemli katkılar sağlanacağına inanılmaktadır. Bunların paralelinde bu araştırmanın amacı; fizik öğretmenleri ve bu dersi alan öğrencilerin AG ortamının manyetizma konusunun öğretiminde kullanılmasına ilişkin görüşlerini ortaya koymak olarak belirlenmiştir. Bu bağlamda araştırmanın amacına ulaşabilmek için aşağıdaki sorulara cevap aranmıştır:

1. Mevcut öğrenme ortamında fizik dersi işlenirken kullanılan teknolojiler öğretmenlere göre yeterli midir?

2. Mevcut öğrenme ortamında manyetizma konusu işlenirken yaşanılan zorluklar ve çözüm yöntemleri öğretmenler açısından nelerdir?

3. AG öğrenme ortamının manyetizma konusu işlenirken sağladığı katkılar nelerdir? 
4. Öğrenci görüşleri doğrultusunda mevcut öğrenme ortamı (sınıf ve laboratuvar) ve AG öğrenme ortamında manyetizma konusu işlenirken yaşanılan tecrübeler nelerdir?

5. Manyetizma konusu işlenirken mevcut öğrenme ortamı (sınıf ve laboratuvar) ve AG öğrenme ortamı öğrenci motivasyonu açısından ne tür farklıııklar göstermektedir?

6. Manyetizma konusu işlenirken mevcut öğrenme ortamı (sınıf ve laboratuvar) ve AG öğrenme ortamı öğrenmeye katkısı açısından ne tür farklııılar göstermektedir?

\section{Yöntem}

\section{Araştırma Modeli}

Araştırmada öğrencilerin görüşlerini ayrıntılı olarak ortaya koymak amacıyla nitel araştırma yöntemlerinden biri olan özel durum çalışması kullanılmıştır. Özel durum çalışmalarında problemler derinlemesine incelenmekte ve bütün araştırma metotları kullanılmaktadır. Bu yöntemin en önemli avantajı araştırmacıya çok özel bir durumun üzerine yoğunlaşma fırsatı vermesidir (Çepni, 2001).

\section{Katılımcılar}

Araştırma 2010-2011 eğitim öğretim yılı ikinci döneminde Trabzon ilindeki bir öğretmen lisesinde gönüllü 3 fizik öğretmeni ve 11. sınıflarda öğrenim gören gönüllü 8 öğrenci ile yürütülmüştür. Çalışma öncesinde söz konusu okulda 11. sınıflardan rastgele üç sınıf belirlenerek manyetizma konusu üç hafta boyunca 11D sınıfında $(N=20)$ araştırmacı tarafından tasarlanan $A G$ ortamıyla, 11A sınıfında $(N=25)$ sınıf ortamıyla ve 11B sınıfında laboratuvar ortamıyla işlenmiştir. Bu öğrencilerden ikisi sınıf ortamında (ÖS1, ÖS2), üçü laboratuvar ortamında (ÖL1, ÖL2, ÖL3), üçü AG ortamında (ÖAG1, ÖAG2, ÖAG3) öğrenim görmektedirler. Öğretmenlere (FÖ1, FÖ2,FÖ3) ise AG ortamıyla ilgili araştırmacı tarafından bir günlük seminer verilmiş ve manyetizma konusu için geliştirilen ortam kullandırımıştır. Çalışmalar sonucunda katılımcıların her üç ortamla ilgili yeterli bilgiye sahip oldukları varsayılmışır.

\section{Veri Toplama Aracı}

Araştırma bünyesinde hazırlanan soruları cevaplandırmak amacıyla üç fizik öğretmeni ve sekiz öğrenci ile odak grup görüşmesi yapılmıştır. Fizik öğretmenlerinin derslerinde ve öğrencilerin fizik öğrenme ortamında AG ortamlarının kullanımlarına ilişkin görüşlerini almak üzere araştırmacı tarafından iki farklı görüşme formu geliştirilmiştir. Hazırlanan görüşme soruları hakkında fizik eğitimi alanında bir uzman ve bilgisayar eğitimi alanında bir uzman olmak üzere toplam iki uzmanın görüşleri alınmış ve gerekli düzenlemeler yapılarak görüşme formuna son şekli verilmiştir. Toplanan veriler kayıt edilmiş, her soruyla ilgili belirlenen ifade ve düşünceler araştırmacı tarafından değerlendirilmiştir. Görüşmelerde fizik öğretmenlerine aşağıdaki sorular sorulmuştur:

- "Bulunduğunuz ortamdaki fizik dersinin işlenebilmesi için teknolojik imkânlar yeterli midir?"

- "Manyetizma konularının öğretilmesinde zorluklar yaşamakta mısınız? Bu zorlukları aşmak için neler yapıyorsunuz?"

- "AG ortamının kullanımı hangi durumlarda size yardımcı olabilir? AG ortamını kullanımı etkinliklerde fayda sağlar mı?

Görüşmelerde öğrencilere aşağıdaki sorular sorulmuştur:

- "Artırılmış gerçeklik ortamı laboratuvar ve sınıf ortamlarıyla karşılaştırıldığında öğrenmeniz açısından avantaj sağlamakta mıdır?"

- "Artııılmış gerçeklik ortamı laboratuvar ve sınıf ortamlarıyla karşılaştıııldığında duygu ve düşüncenizin değişmesine olumlu yönde etki etmekte midir?"

- “Manyetizma konularının öğreniminde öğrenme ortamınız katkı sağladı mı? AG ortamı akademik başarınızın artmasını sağladı mı?"

- "Fizik dersleri AG ile işlenirse etkili olur mu?". 


\section{Verilerin Toplanması}

Araştırmaya katılan öğretmen ve öğrencilere manyetizma konusu kapsamında uygulamalar üç hafta süreyle sınıf ortamında, laboratuvar ortamında ve AG ortamında yürütülmüştür. Uygulama sürecinde elde edilen gözlemler doğrultusunda değerlendirmeler yapılmış, uzman görüşleri de alınarak yarı yapılandırılmış görüşme formu hazırlanmıştır. Bu formun uygulanmasıyla öğrencilerin fiziği özellikle de manyetizma konusunu öğrenmede farklı uygulama alanlarının öğrenci ve öğretmenler üzerine etkisi belirlenmeye çalışılmıştır. Daha sonra öğretmenler ve öğrencilerle ayrı ayrı odak grup görüşmeleri gerçekleştirilmiş ve katılımcılar arası fikir alış verişi sağlanmıştır. Odak grup görüşmesinde bireylerin belirlenen konu hakkında ne düşündüklerini ortaya koymak amaçlanmaktadır. Bu ortamda bulunan bireyler birbirlerinin ortaya koyduğu ifade ve görüşleri duymaktadırlar.

\section{Verilerin Analizi}

$\mathrm{Bu}$ araştırmada veri toplama yöntemi olarak yarı yapılandırılmış görüşme tekniği kullanılmıştır. Bu yöntemde soruların sırası değiştirilerek sorular daha ayrıntılı biçimde açıklanabilmektedir (Çepni, 2001). Araştırma kapsamında, fizik öğretmenleri ve öğrencilerle yapılan odak grup görüşmesi ile elde edilen verilerin değerlendirmeleri sonucunda en yüksek puanlama olarak "evet" bir alt derecedeki puanlama için "kısmen" en alt puanlamada ise "hayır" olarak kategoriler belirlenmiş ve veriler analiz edilmiştir. Görüşmeler ses kayıt cihazı ile kayıt edilmiş daha sonra dijital ortama aktarılmıştır. Elde edilen yanıtlar araştırmacı tarafından analiz edilmiş ve çalışmanın güvenirliliğini artırmak amacıyla görüşme formunu inceleyen uzmanlara kontrol ettirilerek görüşleri alınmıştır. Analiz işlemlerinde her bir katılımcının konuşmaları incelenmiş ve bu çerçevede sınıflandırılarak bulgular bölümünde sunulmuştur.

\section{Bulgular}

Çalışmanın bilimsel araştırma yöntemini oluşturan odak grup görüşmesi esnasında elde edilen veriler aşağıda sunulmuştur. Görüşmelerin yapıldığı fizik öğretmenleri FÖ1, FÖ2 ve FÖ3; sınıf ortamında öğrenim gören öğrenciler ÖS1 ve ÖS2; laboratuvar ortamında öğrenim gören öğrenciler ÖL1, ÖL2 ve ÖL3; AG ortamında öğrenim gören öğrenciler ise ÖAG1, ÖAG2 ve ÖAG3 olarak kodlanmıştır.

Soru1: "Bulunduğunuz ortamdaki fizik dersinin işlenebilmesi için teknolojik imkânlar yeterli midir?" Araştırmaya katılan fizik öğretmenlerinin ilgili soruya verdikleri yanıtlara göre elde edilen bulgularda, birinin "evet", ikisinin "kısmen" görüşünde oldukları ifadelerinden anlaşılmaktadır. Aşağıda söz konusu yanıtlar sırasıyla şu şekildedir:

"Kısmen. Araç-gereç eksikleri giderilmelidir. Özellikle kullanımı kolay, karmaşık olmayan ve konuya uygun türden olmalıdır" (FÖ1).

"KIsmen, eksik malzemelerimiz var. Nova5000 ile ilgili MEB bünyesinde kurslar ve seminerler düzenliyorum. Bununla hassas ve anlık grafikler çizilebiliniyor. Ancak görsel olarak zayıf ve öğrenciye durumları iki boyutlu gösterdiği için öğrencinin kavraması zorlaşıyor" (FÖ2).

"Evet yeterli. Nova5000 ile ilgili deneyimim oldu ancak kurulum ve işlemler bazen çok uzun oluyor" (FÖ3).

Soru2: "Manyetizma konularının öğretilmesinde zorluklar yaşamakta mısınız? Bu zorlukları aşmak için neler yapıyorsunuz?" Araştırmaya katılan fizik öğretmenlerinin ilgili soruya verdikleri yanıtlara göre elde edilen bulgularda, her üçünün "kısmen" görüşünde oldukları ifadelerinden anlaşılmaktadır. Aşağıda söz konusu yanıtlarla vurgulanmaya çalışılan noktalar sırasıyla belirtilmiştir:

"Soyut kavramları içermesi ve görselleştirmeye ihtiyaç duyması. Özellikle öğrenciler yön kavramını algılamada zorluklar çekiyorlar. Sağ el kuralını öğrenmede zorluk yaşıyorlar. Bu durumu örnek çözüp deney yaparak gidermeye çalışıyorum" (FÖ1). 
"Bazı öğrenciler manyetizma ile ilgili konuların zor anlaşıldığını ve yorum yapamadıklarını ifade ediyorlar. Üç boyutlu yön kavramını çizimle anlatmaya çalısııoruz. Bunun daha kolay yolu olabilir. Ayrıca deney ve animasyonlara başvurup kavram yanılgılarının üzerinde duruyorum" (FÖ2).

"Manyetizma konusunda öğrencilerin üç boyutlu düşünmelerinde sıkıntı oluşabilmekte. Bilgisayar destekli simülasyonlar ve benzeri uygulamalarla üç boyutlu açıklamalar yaparak bunu gidermeye çalışıorum" (FÖ3).

Soru3: "AG ortamının kullanımı hangi durumlarda size yardımcı olabilir? AG ortamı kullanımı etkinliklerde fayda sağlar mı?" Araştırmaya katılan fizik öğretmenlerinin ilgili soruya verdikleri yanıtlara göre elde edilen bulgularda, her birinin "evet" görüşünde oldukları ifadelerinden anlaşılmaktadır. Görüşleri aşağıda şu şekilde belirtilmiştir:

"Manyetik alanın görselleştirmesi açısından bu konunun öğretilmesinde kolaylık sağlayabilir" (FÖ1).

"Görselleştirme açısından avantajlı. Aygıtın üzerinde oluşan görselin cihaz üzerinde bir ekranda görülebilir hale getirilmesiyle durum öğrenci için anlaşılması daha kolay bir hal alacaktır" (FÖ2).

"Manyetik alanın değerinin belirlenmesi ve modellenmesi. Üç boyutlu olarak yönlerin algılanması kavramayı kolaylaştırabilir" (FÖ3).gibi cevaplar alınmıştır.

Çalışmanın bilimsel araştırma yöntemini oluşturan odak grup görüşmesi sonucunda öğrencilerden elde edilen yanıtlara aşağıda yer verilmiştir.

Soru1: "Artırılmış gerçeklik ortamı laboratuvar ve sınıf ortamlarıyla karşılaştırıldığında öğrenmeniz açısından avantaj sağlamakta mıdır?" Araştırmaya katılan öğrencilerin ilgili soruya verdikleri yanıtlara göre elde edilen bulgularda, altı kişinin "evet", ikisinin "kısmen" görüşünde oldukları ifadelerinden anlaşıımaktadır. Aşağıda söz konusu yanıtlar sırasıyla şu şekildedir:

"Sınıf ortamda ders sırasında kullanılacak kitap ve kaynakların hazır olması onu diğer ortamlara nazaran daha avantajıl yapmaktadır" (ÖS1).

"Kısmen, sınıf ortamındaki çalışmalarımızda yazılı kaynakların hazır ve elimizin altında olmasından dolayı kayıt tutma ve çalışmada avantaj sağlamakta. Sonrası için elimizde kaynak olarak bulunuyor" (ÖS2).

"Laboratuvar ortamında deneyler yapıyoruz ve günlük hayatla ilişkilendirme şansımız olmaktadır. Sınıf ortamda ise yaptığımız işlemler, formüller ve örnekler olması günlük hayatla ilgili ilişkisini kavramamızı engelliyor" (ÖL1).

"Bence fizik için günlük hayatla ilişkilendirmek daha önemli, formüller yazmak değil." (ÖL2).

"Selenoidin ne olduğunu bilmiyordum. Laboratuvar ortamında kullanılan araç-gereçleri uygulamalar sırasında gördüm. Görsel bir ortam sunuyor" (ÖL3).

"Artırılmış gerçeklik uygulamalarda daha gerçekçi bir ortam sunuyor. Hayali gerçekleştirerek somut bir şekilde bizlere sunuyor" (ÖAG1).

"Artırılmıs gerçeklik ortamının bence fazla avantajı yok, soruları çözmeye katkııı olmadı. Ancak görsellik olarak etkiledi. Güncel bilgilerle bağlantı kurmada yardımcı oldu" (ÖAG2).

"Artırılmıs gerçeklik uygulamalarla öğrenme ortamı daha görsel bir hal aldı. Bu daha iyi algılamaya neden oluyor" (ÖAG3).

Soru2: "Artırılmış gerçeklik ortamı laboratuvar ve sınıf ortamlarıyla karşılaştırıldığında duygu ve düşüncenizin değişmesine olumlu yönde etki etmekte midir?" Araştırmaya katılan öğrencilerin ilgili soruya verdikleri yanıtlara göre elde edilen bulgularda, her birinin "evet" görüşünde oldukları ifadelerinden anlaşılmaktadır. Öğrenciler aşağıdaki noktaları vurgulamışlardır:

"Manyetizma konusunu işlemede anlaşılabilmesi için sınıf ortamı değil de laboratuvarda işlenirse daha iyi olur. Bazen eğer konu anlaşılmazsa fizikten nefret noktasına gelinebiliyor" (ÖS1). 
"Bu ortam (sınıf) merak uyandırmadı. Görsel olsaydı dikkatimi çekerdi ve zevk alırdım. Ama sınıf ortamında kendimi rahat hissediyorum çünkü laboratuvardan ders işlenseydi dikkatimi sürekli etkinliklere vermem gerekiyordu. Eğer bir noktayı kaçırırsam konuyu anlamama olayı olurdu" (ÖS2). "Sınıf ortamını terk ederek laboratuvara gittiğimizde yeni ortamda daha iyi adapte oluyoruz" (ÖL1). "Deneylerde bana manyetizma konusu ilginç geldi. Konu cazip geldi" (ÖL2).

"Bu ortamda yapılan iş daha güzel geldi. Sınıfta konuyu işleyip geçiyorduk ancak fiziği kullanabileceğimi bilmek bende fiziğe karşı sevgi oluşturuyor" (ÖL3).

"AG de kullandığım alet farklı bir alet geldi bana, her şeyi ölçümlerle yapılabileceğini gösterdi, dikkatimi çekti. Benim fiziğe karşı ilgim var, ama fiziğin bu şekilde işlenmesi benim için daha iyi oldu" (ÖAG1).

"Dikkatimi çekti, sonuçta yeni bir teknoloji. Duygu ve düşünce olarak bir değişime neden olmadı, fiziği seviyorum hala seviyorum" (ÖAG2).

"Geliştirilen bu cihaz elimizde olsa istediğimiz ölçümü yapabiliriz. Cihazın kendisi bile merak uyandırdı. Nasıl çalıştığını nasıl ölçtüğünü dikkatle inceledim. Merak uyandırdı. Gözümüzle görünce fizik korkumuz azaldı" (ÖAG3).

Soru3: "Manyetizma konularının öğreniminde öğrenme ortamınız katkı sağladı mı? AG ortamı akademik başarınızın artmasını sağladı mı?" Araştırmaya katılan öğrencilerin ilgili soruya verdikleri yanıtlara göre elde edilen bulgularda, dört kişinin "evet", dört kişinin ise "kısmen" görüşünde oldukları ifadelerinden anlaşılmaktadır. Aşağıda söz konusu yanıtlar sırasıyla şu şekildedir:

"Sınıf ortamının orta düzeyde bir yararı var ama manyetizma konusunda istenilen düzeyde yararlı olmadı" (ÖS1).

"Sınıf ortamında yapılan etkinliklerin öğretmeni dinlemek tahtaya yazılarımızı yazıp konu ile ilgili kaynak oluşturmak açısından avantajlı ama görsellik olarak eksik ve kalıcılığı zayıf" (ÖS2).

"Laboratuvardaki etkinlikler yararlı, yapılan etkinlikler doğrultusunda konu anlaşıldığında daha önceki eksikliklerim giderilmiş oluyor" (ÖL1).

"ilköğretimde laboratuvar etkinliklerini yapamıyorduk, ancak burada manyetizma ünitesi etkinliklerini yapabildik" (ÖL2).

"Laboratuvar etkinlikleri güzel ama zaman çok alıyor" (ÖL3).

"Artırılmış gerçeklik etkinlikleri laboratuvarda uygulanırsa iyi olur" (ÖAG1).

"Artırılmış gerçeklik etkinliklerinde yeni cihaz kullandık. Bu da daha iyi oldu." (ÖAG2).

"Laboratuvar ile kullanıldığında, destekleyici olarak kullanılacaksa tam fayda alırız. Manyetik alanın yönünü ve şiddetini görsel olarak rahatlıkla gördük" (ÖAG3).

Soru4: "Fizik dersleri AG ile işlenirse etkili olur mu?" Araştırmaya katılan öğrencilerin ilgili soruya verdikleri yanıtlara göre elde edilen bulgularda, altı kişinin "evet”, ikisinin "kısmen" görüşünde oldukları ifadelerinden anlaşılmaktadır. Öğrenciler aşağıdaki noktaları vurgulamışlardır:

"Konuya göre değişmekte, örneğin manyetizma ünitesinde değişmeyen manyetik alan etkinliğinde, selenoidin etrafında oluşan manyetik alanı tam anlayamadık" (ÖS1).

"Artırılmış gerçeklik ve laboratuvarda işlenseydi deneylerde adım adım anlayarak işlemleri yapardık". (ÖS2).

"Sınıfta kitap okuyoruz ve konu önümüzde duruyor. Laboratuvarda konuyu bize bir canlı gibi gösteriyor" (ÖL1).

"Uygulamalardan sonra durumları çözümleme ve analizinde daha önce yapılan deneylerle örnekler gösterebiliyoruz" (ÖL2).

"Sınıf ortamı görsel olarak zayıf kalıyor. Laboratuvar ortamında bu görsellik daha avantajlı oluyor" (ÖL3).

"Sınıfta hep hayal ediyoruz ve bilgileri yazıyoruz. Burada uygulamalı ve görsel olarak eğitim alıyoruz.

Bu da etkili oluyor ancak yazılı dokümanlarla desteklenmelidir bu tür etkinlikler" (ÖAG1).

"Artırılmıs gerçeklik laboratuvarı daha cazip hale getirdi" (ÖAG2). 
"Artırılmış gerçeklikten sonra artık çevremdeki her bir nesneyi ve cihazı gördügü̈mde "Acaba bu manyetik alana sahip midir, değil midir?" diyerek kendi kendime soruyorum. Her birinde aynı bilgiler veriliyor ancak görsellik olarak avantajlı görünüyor" (ÖAG3).

\section{Sonuç, Tartışma ve Öneriler}

Araştırma sonucunda elde edilen bulgularda araştırma sorularına cevap aranmıştır. Elde edilen verilere göre; "mevcut öğrenme ortamında fizik dersi işlenirken kullanılan teknolojiler öğretmenlere göre yeterli midir?" sorusu ile ilgili, araştırma süresince fizik öğretmenleriyle yapılan mülakatlardan fiziği öğretmede fizik laboratuvarlarından yararlandıkları aşamada standart deney takımları ve Nova5000 gibi araç gereçlerden yararlandıkları tespit edilmiştir. Fizik alanında geliştirilecek bir teknolojinin öncelikli olarak basit, ucuz ve kullanım kolaylı̆ı̆ı sahip olmasına dikkat ettiklerini, görsel olarak zengin ve öğrenciye durumları üç boyutlu gösterebilen ortamlar olmalarıyla fiziği öğretmede görselleştirmelerin ve somutlaştırmaların yararlı olduğunu düşünmektedirler. Öğretmenlerin bu düşüncelerine literatürde destekleyen çalışmalar bulunmaktadır (Chabay ve Sherwood, 2006; Demirci ve Çirkinoğlu, 2004; Kocakülah, 1999).

“Mevcut öğrenme ortamında manyetizma konusu işlenirken yaşanılan zorluklar ve çözüm yöntemleri öğretmenler açısından nelerdir?" sorusu ile ilgili, öğretmenler fiziği özellikle de manyetizmayı öğretmek adına manyetik alanın görselleştirilmesi ve somutlaştırılmasında, üç boyutlu yön kavramını algılatılmasında ve sağ el kuralının öğretiminde deney ve animasyonlara başvurarak kavram yanılgılarının üzerinde durduklarını ifade etmektedirler. Chabay ve Sherwood (2006) yaptıkları çalışmada öğrencilerin manyetizma konularını diğer konulardan daha zor bulduklarına değinmişlerdir. Araştırmacılar bunu manyetizmanın çokça soyut kavramları içermesinden ve bu aşamada ilk defa üç boyutlu düşünme ve gözünde canlandırma becerilerini kullanmadaki güçlüklerin oluşmasından kaynaklandığını ifade etmişlerdir. Benzer bulgulara Bagno ve Eylon (1997)'un çalışmalarında da rastlanmıştır.

"AG öğrenme ortamının manyetizma konusu işlenirken sağladığı katkılar nelerdir?" sorusu ile ilgili, araştırma sonucunda elde edilen bulgularda öğretmenler artııılmış gerçeklik ortamlarının fiziği özellikle de manyetizmayı öğretmek adına manyetik alanın görselleştirilmesi ve somutlaştırılmasında yararlar sağlayabileceğini, artııımış gerçeklik ortamında manyetik alanın üç boyutlu şekillerle görselleştirilmesiyle öğrencilerin etkinliklerde anlatılan durumlar arasındaki farklııkları daha kolay açıklayabildiklerini, konunun kavramasında kolaylıkların olabileceğini düşündükleri gözlenmiştir. Manyetizma konusunun AG ile öğretimini konu alan Buesing ve Cook (2013), Macedo, Fernandes, Lima ve Biazus (2012), Matsutomo, Miyauchi, Noguchi ve Yamashita (2012) çalışmalarında da öğretmenlerin ifadelerini destekler niteliktedirler.

"Öğrenci görüşleri doğrultusunda mevcut öğrenme ortamı (sınıf ve laboratuvar) ve AG öğrenme ortamında manyetizma konusu işlenirken yaşanılan tecrübeler nelerdir?" sorusu ile ilgili, sınıf ortamındaki öğrenciler, bu ortamın sağlamış olduğu kitap ve kaynakların hazır bir şekilde bulunması, ders sırasında kayıt tutulabilmesi durumlarında avantaj sağladığıı belirtmişlerdir. Laboratuvar ortamında ders gören öğrenciler, bu ortamda deneylerin yapılmasıyla birlikte konuları günlük hayatla ilişkilendirme şanslarının olduğu, bunun da fiziği öğrenme açısından olumlu yönde tutumlarıın gelişmesini sağladığını belirtmişlerdir. Artırıımış gerçeklik ortamındaki öğrenciler ise bu ortamın uygulamalarda daha gerçekçi bir ortam sunması, görselliği şekillendirmesi, kavramları somutlaştırması ile ön plana çıktığııı ifade etmişlerdir.

Literatür incelendiğinde laboratuvarların fiziğin öğretilmesinde öğrencilere yaparak yaşayarak öğrenme fırsatını vermesinden dolayı önemi vurgulanmaktadır (Ayas, Akdeniz ve Çepni 1994; Böyük ve Erol, 2008; Chiappetta ve Koballa, 2002). Ayrıca artııılmış gerçeklik ortamlarla uygulamaya katılan kişinin bizzat uygulayıcı olması, kişilerin deneyim sahibi olarak kişisel deneyimlerinin artmasına yardımcı 
olmaktadır (Müller ve Ferreira, 2004). Bu bağlamda elde edilen sonuçlarla literatür paralellik göstermektedir.

"Manyetizma konusu işlenirken mevcut öğrenme ortamı (sınıf ve laboratuvar) ve AG öğrenme ortamı öğrenci motivasyonu açısından ne tür farklılıklar göstermektedir?" sorusu ile ilgili, sınıf ortamındaki öğrenciler bu ortamın fiziği anlamada tam olarak yardımcı olmadığı durumlarda öğrencilerin fizikten nefret etme derecesine gelebildiklerini, öte yandan bu ortamlarda öğrencilerin pek de aktif olmadıkları için dikkatlerinin sürekli olması konusunda kendilerini zorunlu hissetmediklerini ifade etmişlerdir. Laboratuvar ortamındaki öğrenciler; deneylerin yapılması ile öğrencilere konunun daha cazip geldiğini ve sadece fizik konusunu işleyip geçmek yerine bu konunun hangi alanlarda, ne şekilde kullanıldığının öğrenciler tarafından bilinmesinin aslında fiziğe karşı sevgi beslemelerine yardımcı olduğunu ifade etmişlerdir. Artırılmış gerçeklik ortamındaki öğrenciler ise yeni bir teknolojinin kullanılması sebebiyle ve konuyu öğrenmede onlara yardımcı olması için geliştirilen cihazın konuyu görselleştirmesinin, fiziğe karşı olan korkularını yenmede katkı sağladığını ve bu ortamı tercih ettiklerini ifade etmişlerdir.

Araştırma sonucuna paralel olarak Finkelstein, Perkins, Adams, Kohl ve Podolefsky (2005) yaptıkları çalışmalarda da katılımcı grupların bu artırılmış gerçeklik ortamının öğrencilerin fiziğe karşı ilgilerini ve cesaretlerini artırdığını tespit etmişlerdir. Bu çalışmanın yeni bir teknoloji ile yapılması öğrencilerin motivasyonunu artırıp dikkatlerini çekmiş ve bu ortamı istenilen bir ortam haline getirmiştir.

“Manyetizma konusu işlenirken mevcut öğrenme ortamı (sınıf ve laboratuvar) ve AG öğrenme ortamı öğrenmeye katkısı açısından ne tür farklılıklar göstermektedir?” sorusu ile ilgili, Sınıf ortamındaki öğrenciler sınıf ortamının yapılan etkinliklerde özellikle de manyetizma konusunda yararının istenilen düzeyde olmadığını ifade etmişlerdir. Laboratuvar ortamındaki öğrenciler bu ortamın deneylerin yapılması açısından fayda sağladığını söylemişlerdir. Artırılmış gerçeklik ortamındaki öğrenciler ise bu ortamın laboratuvar etkinliklerine destekleyici olması ve laboratuvar ortamlarına görselliği katarak verimliliği arttırdığını ifade etmişlerdir. Laboratuvar ortamının fizik öğretiminde etkililiğini Akdeniz, Çepni ve Azar (1998), Ayas vd. (1994), Hofstein, Navon, Kipnis ve Mamlok (2005) çalışmalarında da vurgulamışlardır. Bu çalışmaların sonucu araştırma sonuçlarını desteklemektedir.

Sınıf ortamındaki öğrenciler kendi ortamlarının dikkat çekme ve merak uyandırma konusunda işlenen konuya göre farklılık gösterdiğini ancak manyetizma konusunun anlaşılmasında uygun bir ortam olmadığını ifade etmişlerdir. Laboratuvar ortamındaki öğrenciler, deneylerin yapılmasıyla ilgilerinin çekildiğini ve bu ortamın manyetizma konusunu daha ilginç bir duruma getirdiğini ifade etmişlerdir. Artırılmış gerçeklik ortamındaki öğrenciler ise bu ortamda yeni teknolojinin kullanıldığını, bunun bile tek başına merak uyandırdığını söylemişlerdir. Öğrenciler; bilim ve teknolojinin birbirini nasıl etkilediğini, toplum ve çevre ile etkileşimi analiz etme gibi durumların artırılmış gerçeklik ortamlarının sağladığı avantajlar olarak gösterilmesiyle, Artırılmış Gerçeklik ortamlarının öğrencilerin olayları daha iyi anlama ve kavramalarına yardımcı olacağını ifade etmişlerdir. Ayrıca bu ortamın uygulamalarda daha gerçekçi bir ortam sunması, görselliği şekillendirmesi, kavramları somutlaştırması ile ön plana çıktığını ifade etmişlerdir.

Winkler vd. (2002), Finkelstein vd. (2005) yaptıkları araştırmalarda artırılmış gerçeklik ortamıyla öğrencilerin öğretilmeye çalışılan kavramları daha iyi öğrendikleri, anlatılmak istenen bilgileri daha kolay kavradıkları ve hatta gerçek deneylerle dahi görülemeyecek durumları kolaylıkla görebildiklerini vurgulamışlardır. Bu araştırmada elde edilen bulgularda söz edilen durumlar literatürden elde edilen bulgularla paralellik göstermektedir. Ayrıca Böyük, Demir ve Erol (2010) çalışmalarında laboratuvar kullanan öğrencilerin derse olan ilgilerinin arttığını ve böylelikle etkili bir öğrenmenin gerçekleşmesinde laboratuvarın etkisini vurgulamışlardır. Laboratuvar ve artırılmış gerçeklik ortamlarındaki öğrenciler kendi ortamlarının fayda sağladığını vurgulamışlar ve elde edilen bu sonucun Böyük vd. araştırmalarında elde edilen bulgularla paralellik gösterdiği gözlenmiştir. Araştırmada belirlenen problemlere ilişkin yapılan incelemeler sonucunda aşağıdaki sonuçlara ulaşılmıştır: 
1. Fizik öğretmenleri fizik dersinin işlenebilmesi için laboratuvarlardan yararlandıkları fakat kullanılan teknolojilerin kısmen yeterli olarak görmektedirler.

2. Fizik öğretmenleri manyetizma konularında manyetik alanın somutlaştırılması, üç boyutlu yön kavramının algılanması ve sağ el kuralının öğretilmesinde öğrenci açısından kısmen zorluk yaşamaktadırlar.

3. Fizik öğretmenleri artırımış gerçeklik ortamlarının manyetizma konusu işlenirken kolaylıklar sağlayabileceğini ön görmektedirler.

4. Öğrenciler artırılmış gerçeklik ortamını laboratuvar ve sınıf ortamlarına nazaran kısmen de olsa avantajlı olarak görmektedirler.

5. Öğrenciler artırılmış gerçeklik, laboratuvar ve sınıf ortamlarının kendi duygu ve düşüncelerine etkilerinin olduğuna katılmaktadırlar.

6. Öğrenciler artırılmış gerçeklik ortamının akademik başarıları üzerine olumlu etkisinin olduğunu ifade etmektedirler.

Araştırmadan çıkarılan sonuçlara göre şu önerilerde bulunulabilir:

1. Fizik dersinde manyetizma konusunun dışında anlaşılması ve görselleştirilmesi zor olan diğer konular için de artırımış gerçeklik ortamları tasarlanmalıdır.

2. Milli Eğitim Bakanlı̆̆ı'nın (MEB) Fatih projesi kapsamında ortaöğretim basamağı için artırılmış gerçeklik ortamlarının farklı konularda da çeşitlendirilerek kullanılmasının yararlı olacağı düşülmektedir. Ayrıca geliştirilen materyal MEB'teki bilişim teknolojileriyle uyumlu olduğundan bu sistemde öğretim materyali olarak kullanılabilir. Fatih projesinin uygulamaya geçirilmeye çalışıldığı şu günlerde bu tür çalışmaların artırılması ve farklı materyallerin de içinde bulunduğu akademik çalışmaların yapılması gerekmektedir.

3. Ortaöğretimde yer alan farklı dersler için de artırılmış gerçeklik ortamları oluşturulabilir. Böylece öğrencilerin fizik dersinde yer alan manyetizma konusunda olduğu gibi diğer derslerin anlaşılması zor olan konuların öğretilmesinde de etkili olabileceği düşünülmektedir.

4. Artırılmış gerçeklik ortamları yeni bir teknoloji olduğundan öğretmenlerin bu teknolojiden haberdar olmaları ve derslerinde daha etkili kullanabilmeleri amacıyla MEB hizmet içi eğitim programlarına artırılmış gerçeklik gibi yeni ortamları dâhil ederek bu programlar çerçevesinde öğretmenlerin bilgilendirilmesini sağlayabilir.

5. Fizik dersi genellikle öğrencilerin korktukları ve anlamakta zorlandıkları dersler arasında yer almasından dolayı öncelikle öğrencilerde fiziğe karşı olumlu tutum ve davranış geliştirebilecekleri bunun yanı sıra duygu ve düşüncelerini olumlu yönde geliştirebilecekleri öğrenme ortamlarıyla etkileşim halinde olması sağlanmalıdır.

6. Öğrencilerin ifadelerinden artırılmış gerçeklik ortamlarının onların duygu ve düşüncelerini olumlu yönde etkilediği anlaşılmakta ve bu ortamların eğitim öğretim sürecine dâhil edilmesi önerilmektedir.

\section{Kaynakça}

Akdeniz, A. R., Çepni, S. \& Azar A. (1998). Fizik öğretmen adaylarının laboratuar kulanım becerilerini geliştirmek için bir yaklaşım. III. Ulusal Fen Bilimleri Eğitimi Sempozyumu, Karadeniz Teknik Üniversitesi, Trabzon.

Alouf, J. L. \& Bentley, M. L. (2003). Assessing the impact of inquiry-based science teaching in professional development activities, PK-12, Paper presented at the Annual Meeting of the Association of Teacher Educators, Jacksonville, Florida.

Ayas, A., Akdeniz, A.R. \& Çepni, S. (1994). Fen bilimlerinde laboratuvarın yeri ve önemi-I. Çağdaş Eğitim, 19, 21-25.

Bagno, E. \& Eylon, B.S. (1997). From problem solving to knowledge structure: an example from the domain of electromagnetism. American Journal of Physics, 65 (8), 726-736. 
Böyük U., Demir, S. \& Erol, M. (2010). Fen ve teknolojileri dersi öğretmenlerinin laboratuar çalışmalarına yönelik görüşlerinin farklı değişkenlere göre incelenmesi. TUBAV Bilim Dergisi, 3(4), 342-349.

Böyük, U. \& Erol, M. (2008). Türkiye'de fen bilgisi laboratuarları: zorluklar ve öneriler, International Journal on Hands-on Science, 20, 1-6.

Buesing, M. \& Cook, M. (2013). Augmented reality comes to physics. The Physics Teacher, 51, 226.

Chabay, R. \& Sherwood, B. (2006). Restructuring the introductory electricity and magnetism course. American Journal of Physics, 74(4), 329-336.

Chiappetta, E. L. \& Koballa, T. R. (2002). Science Instruction in the middle and secondary schools (5th ed.). Upper Saddle River, NJ: Pearson.

Çepni, S. (2001). Araştırma ve Proje Çalışmalarına Giriş. Trabzon: Erol Ofset.

Dagher, Z. (1995). Review of studies on the effectiveness of instructional analogies in science education. Science Education, 79 (3), 295-312.

Demirci, N. \& Çirkinoğlu, A. (2004). Öğrencilerin elektrik ve manyetizma konularında sahip oldukları ön bilgi ve kavram yanılıılarının belirlenmesi. Türk Fen Eğitimi Dergisi, 1 (2), 116-136.

Duphin, J. J. \& Johsua, S. (1989). Analogies and modeling analogies in teaching: some examples in basic electricity. Science Education, 73 (2), 207-224.

Finkelstein, N. D., Perkins, K. K., Adams, W., Kohl, P. \& Podolefsky, N. (2005). Can computer simulations replace real equipment in undergraduate laboratories?. In AIP Conference Proceedings, 790, p. 101.

Grabinger S. (1999). Instructional strategies in distance science courses: Can the web improve undergraduate science education?. Retrieved March 05, 2012, from http://web:uccs.edu/bgaddis/leadership/litreviewD2.htm.

Greca, I. M. \& Moreira, M. A. (2000). Mental models, conceptual models, and modeling. International Journal of Science Education, 22(1), 1-11.

Hofstein, A., Navon, O., Kipnis, M. \& Mamlok-Naaman, R. (2005). Developing students' ability to ask more and better questions resulting from inquiry-type chemistry laboratories. Journal of Research in Science Teaching, 42(7), 791-806.

Jonassen, D.H., Pech, K.L. \& Wilson, B.G. (1999). Learning with technology: a constructivist perspective. New Jersey: Merrill, 4, 67-68.

Kirkley, J., Kirkley, S., Myers, T., Borland, C., Swan, M., Sherwood, D. \& Singer, M. (2005). Embedded training for objective force warrior: using problem-based embedded training (PBET) to support mixed and virtual reality simulations. US Army Research Institute for the Behavioral and Social Sciences Technical Report.

Kocakülah, M. S. (1999). A study of the development of Turkish first year university students' understanding of electromagnetism and the implications for instruction. Unpublished PhD thesis, University of Leeds, Leeds.

Lawson, D. \& Lawson, A. (1993). Neural principles of memory and a neural theory of analogical insight. Journal of Research in Science Teaching, 30 (10), 1327-1348.

Liu W., Cheok A.D., Ling C. \& Theng Y., (2007). Mixed reality classroom-learning from entertainment, DIMEA , 65-72.

Macedo S.H, Fernandes F.A., Lima J.V. \& Biazus M.C.V. (2012). Learning object to teach the interaction between two magnetics using augmented reality. Journal of Educational and Instructional Studies, 2(4), 1-12.

Matsutomo, S., Miyauchi, T., Noguchi, S. \& Yamashita, H. (2012). Real-time visualization system of magnetic field utilizing augmented reality technology for education. Magnetics, IEEE Transactions on, 48(2), 531-534. 
McDermott, L. C. (1993). How we teach and how students learn: a mismatch?. Am J. Phys. 61, 295-298.

Müller, D. \& Ferreira, J. M. (2003). MARVEL: a mixed reality learning environment for vocational training in mechatronics. In Proceedings of the Technology Enhanced Learning International Conference,(TEL'03), Milan, Italy.

Serway A. \& Beichner R. (2002), Fen ve Mühendislik için Fizik (Çolakoğlu K., Çev.) Ankara: Palme Yayıncılık.

Uşun S., (2003). Eğitim ve öğretimde bilgisayarın yararları ve bilgisayardan yararlanmada önemli rol oynayan etkenlere ilişkin öğrenci görüşleri. Kastamonu Eğitim Dergisi, 2(11), 367-378.

Winkler, T., Herczeg, M., \& Kritzenberger, H. (2002). Mixed reality environments as collaborative and constructive learning spaces for elementary school children. In World Conference on Educational Multimedia, Hypermedia and Telecommunications, 2002(1), 1034-1039.

Winn, W., Windschitl, M., Fruland, R. \& Lee, Y. (2002). When does immersion in a virtual environment help students construct understanding. In Proceedings of the International Conference of the Learning Sciences, 497-503.

Zagoranski, S. \& Divjak, S. (2003). Use of augmented reality in education. IEEE, 2, 339-342. 
Mustafa Serkan ABDÜSSELAM - Pegem Eğitim ve Öğretim Dergisi, 4(1) 2014, 59-74 